\title{
Plandemic doctor
}

\author{
Jared Bly ${ }^{1}$ \\ Received: 29 August 2020 / Accepted: 11 September 2020 / Published online: 4 January 2021 \\ (c) Canadian Association of Emergency Physicians (CAEP)/ Association Canadienne de Médecine d'Urgence (ACMU) 2020
}

Keywords Pandemic $\cdot$ History of medicine $\cdot$ Plague doctor

I have a plague-doctor mask that I like. Not really to wearit creeps people out-but for what it stands for. My mask is symbolic of health-care providers in another era, doing what they could with what they had. It seems relevant today.

Pandemics are not new. Devastating disease outbreaks, spreading across countries, continents, and oceans have been with humankind always. After all, "microbes refuse to respect political borders" [1]. I hear (or say) "unprecedented times" at least five times a day. But pandemics are not unprecedented at all. We are asking the same questions that have plagued (sorry, could not resist) people for ages. For that reason, I prefer "plague" to "pandemic". No out of some masochistic desire, but a nod to our worthy predecessors. What was that quote about repeating history?

George Santayana is often quoted something like "Those who do not know history are doomed to repeat it". It might be that history repeats itself regardless of one's awareness of the subject. See Clairmont, N. 2013. "Those Who Do Not Learn History Are Doomed To Repeat It.” Really? Big Think. https://bigthink.com/ the-proverbial-skeptic/those-who-do-not-learn-histo ry-doomed-to-repeat-it-really.

The similarity between the modern plague of COVID-19 and previous ones is eery. The furor over chloroquine is a sad repetition of history. Quinine was a hopeful 'magic bullet' in the middle ages, too. Putting one's trust in a dubious cure is as old as time.

Electronic supplementary material The online version of this article (https://doi.org/10.1007/s43678-020-00002-w) contains supplementary material, which is available to authorized users.

Jared Bly

jrdbly@gmail.com

1 Edmonton, Canada
"One recipe instructed: take an ounce of the best gold, add eleven ounces of quicksilver, dissolve by slow heat, let the quicksilver escape, add forty-seven ounces of water of borage, keep airtight for three days over a fire, and drink until cured, or, as was more probably, death supervened. At least the high price of gold ensured that not many invalids could thus be poisoned [2]."

The only surprising thing is that in modern times, it is newsworthy (Man dead from taking chloroquine product after Trump touts drug for coronavirus, Forbes. March 23, 2020. Available from https://www.forbes.com/sites/tarah aelle/2020/03/23/man-dead-from-taking-chloroquine-after -trump-touts-drug-for-coronavirus/\#a9e6edd72e91). Maybe that old antibiotics are not prohibitively expensive is the only thing that has changed. Quinine has not panned out this time around either [3].

The other medieval terminology that is relevant is "pesthouses". Whatever image that may bring to mind, to the medieval mind it probably conjured up images of compassion and respite. Pesthouses were designated facilities "to take in the sick and dying" [1]. I think of my downtown urban hospital, the gamut of characters we see, from rich to poor, extremely unwell too, well, well. Plague or not, we aspire to provide a haven to anyone, but especially the sick and dying.

The plague doctors have gotten a bad rap for being spooky. Through the dark lens of history, we see them as useless at best, charlatans at worst. But remember, if they were walking around a plague-infested city in their PPE, it was because they hadn't heeded the common advice to flee to the fresh air [5]. We know that doctors were at the bedside of many of the sick and dying and that they themselves, were often victims [4]. If they were in it for gain, they got what they deserved. More likely, compassion and duty were the prime motivation. 
Besides death and disability, plagues also bring progress. "Epidemics... are a major part of the 'big picture' of historical change and development" [1]. The middle ages version changed the relationship between employer and 'employee' (peasant, probably closer to slave). With much of the workforce dying off, the supply decreased [1]. Labourers could ask for higher wages and hike over to the next farm if their paycheck was inadequate.

Plagues foster changes to religious, social, and philosophical structures. The exceptionally high death rate among clergy during the European plagues of the 14th through seventeenth centuries led to both waning authority of the church as well as increased religiosity. A resentment of wealth emerged. Changing philosophies hastened the reformation [1]. You could say that the Black Death brought light to the dark ages [5].

Will our current plague bring enlightenment? The cliché "it is too early to tell" is fitting. But the race to produce a vaccine in record time is indicative of some progress. Masking and social distancing are not new concepts, but they have found a new adherence, at least in my circles. Will we see cultural or philosophical changes? Will handshakes disappear, permanently replaced by fist bumps or other salutations at a safer distance? Will masks become permanent accessories? Will I ever be able to wear my plague mask in public without a lot of raised eyebrows, head shaking, or crying babies?

Will our descendants look back at our time and giggle, or shudder in mock horror at our creepy costumes? Will future halloweeners sport yellow gowns, fake N95's, oversized goggles, and blue nitrile gloves? Will they laugh condescendingly at our debates about aeresolization, fomite transmission, and incubation periods? Is there any reason to think that human understanding will not have evolved from here as we have from the past?
Maybe you won't accept my proposal to call COVID-19 a plague. I'm sure no one will accept my idea to call any hospital a pesthouse. But I hope we will remember past plagues to heed conscientious experts and leaders guiding us with sound, though incomplete science. We scoff at public health officials, masking/sanitizing/distancing at our own risk. The rosemary and juniper in the beak of the plague doctor's mask may not have warded off evil humours, but the transmission was certainly decreased by the covering. Close, but not exact by current scientific understanding. "Often the attempt [to eradicate outbreaks] failed, but the concepts guiding them still underlie public health measures to confront microbial assaults" [1]. Will some current practices be similarly unintentionally beneficial? It's hard to imagine that we do not know all there is to know, but utterly inconceivable, too. We're not so different than medieval Europe, “...groping towards the future, with one nervous eye always peering over its shoulder toward the past" [2]. At least, I hope we keep an eye on the past as we grope our way forward.

\section{References}

1. Snowden FM. Epidemics and society: from the black death to the present. Yale University Press, Yale 2019. Doi: https://doi. org/10.2307/j.ctvqc6gg5.

2. Ziegler P. The black death. London: Faber \& Faber; 2013.

3. Roustit M, Guilhaumou R, Molimard M, Drici M, Laporte S, Montastruc JL. Chloroquine and hydroxychloroquine in the management of COVID-19: much kerfuffle but little evidence. Therapies. 2020. https://doi.org/10.1016/j.therap.2020.05.010.

4. Wray SK. Boccaccio and the doctors: medicine and compassion in the face of plague. J Mediev Hist. 2004;30(3):301-22. https:// doi.org/10.1016/j.jmedhist.2004.06.005.

5. Yumagulova, L. Editor's note. Haznet. Spring/summer 2020;14(1). Available from www.haznet.ca. Accessed 22 Oct 2020. 